\title{
Complete atrioventricular block during central venous catheter placement with pre-existing left bundle branch block: Preparedness guidelines
}

\author{
Sachin Kumar Amruthlal Jain, Gokulakkrishna Subhas \\ Saba Darda, Shukri David
}

\begin{abstract}
Introduction: Injury to the right bundle causing Right Bundle Branch Block (RBBB) is a known complication of central line placement. Complete heart block may result in patients with pre-existing Left Bundle Branch Block (LBBB). There are no organized guidelines for preparedness in such condition. Case Report: Seventy-eight-year old woman presented with intraparenchymal hemorrhage. Venous access was obtained in the right subclavian vein and guide wire was passed. As the catheter was passed over the guidewire, the rhythm went in complete heart block. She was paced with an external pacemaker. Review of her EKG revealed pre-existing LBBB. Conclusion: Clinicians should check the EKG before attempting central line placement in an elective/semi-emergent situation. Familiarize with the catheter and guide wire lengths/markings of the available kit.
\end{abstract}

Keywords: Complete heart block, Pre-existing left bundle branch block, Upper central venous line placement

Sachin Kumar Amruthlal Jain, Gokulakkrishna Subhas, Saba Darda, Shukri David

Affiliations: Section of Cardiology, Department of Internal Medicine, Providence Hospital and Medical Centers, Southfield, MI, USA.

Corresponding Author: Sachin Kumar Amruthlal Jain, Department of Internal Medicine, Providence Hospital and Medical Centers, 16001 W. Nine Mile Road, Southfield, MI. 48075, USA; Phone: 248961 1758; Fax: 2488493151; Email: doctorsachin@gmail.com

Received: 26 January 2011

Accepted: 25 March 2011

Published: 30 April 2011
$* * * * * * * * *$

Jain SKA, Subhas G, Darda S, David S. Complete atrioventricular block during central venous catheter placement with pre-existing left bundle branch block: Preparedness guidelines. International Journal of Case Reports and Images 2011;2(4):15-18.

$* * * * * * * * *$

doi:10.5348/ijcri-2011-04-29-CR-4

\section{INTRODUCTION}

The central venous access is one of the most common procedures done in the emergency rooms, intensive care units and on patients in monitored beds. Heart block and arrhythmia are known complications of central venous and pulmonary artery cardiac catheterization. Injury to the conducting system of the heart often involves the right bundle causing right bundle branch block (RBBB) and in patients with preexisting left bundle branch block (LBBB), complete heart block may result. The impairment of the right bundle is usually transient with recovery in hours. This complete atrioventricular block is an infrequent but potentially life-threatening complication of central venous access catheter placement.

Though cases have been reported about the occurrence of complete heart block during central venous access catheter placement in patients with preexisting LBBB, there are no organized guidelines for preparedness in such condition. We present a case of complete heart block during insertion of a subclavian central venous catheter in an elderly patient with a pre-existing LBBB. We have come up with guidelines for dealing with patients while obtaining central venous access with pre-existing LBBB. 


\section{CASE REPORT}

A 78-year-old woman with past medical history of uncontrolled hypertension was transferred to our institution from a different facility for management of acute intraparenchymal hemorrhage. The patient was found to be entangled in her walker and unresponsive with unknown downtime. EMS was activated and transferred to a facility where CT scan of the brain showed right intracerebral hemorrhage with Glasgow coma scale score of 4 . On arrival at our institution, she was intubated. She was unresponsive with pin point pupil. Her vitals included blood pressure of $166 / 76$, heart rate of 76 and regular, and oxygen saturation of $100 \%$ on ventilation. She was hemodynamically stable and needed a central venous access for fluid management and medications. After obtaining venous access in right subclavian vein with a single stick of needle, a guide wire was passed till approximately $20 \mathrm{~cm}$. As the catheter was passed over the guidewire, the rhythm went in to sinus block and later in to complete heart block, with no ventricular escape rhythm (Figure 1). The procedure was immediately stopped and the catheter with guide wire was pulled out. She was paced with external pacemaker for the next 12 hours. She reverted back to her baseline rhythm. Review of her EKG post procedure revealed pre-existing LBBB (Figure 2).

\section{DISCUSSION}

Central venous access catheters are placed for a number of clinical indications, including large-caliber venous access, hemodialysis, and venous pressure monitoring. It is preferable to obtain access either via subclavian vein or internal jugular vein, compared to the femoral vein because of an increased risk of infection. Most of the emergent and semi-emergent central venous catheter placements are performed at the bedside in a "blind" fashion, with adjustment of the final catheter tip position using chest radiographs.

Common immediate complication of line placement include atrial/ventricular dysrhythmias, pneumo/hemo/hydrothorax, cardiac tamponade and mediastinal fluid collection. [1] Atrial and ventricular arrthymias are known to occur frequently during central venous catherizations. The complete transient atrioventricular block during placement of central venous catheter is a rare occurrence. The incidence of RBBB during right heart catherization is about $5 \%$. [2] This RBBB is usually caused due to mechanical trauma by the guide wire. The right bundle branch is very superficially placed anatomically in the right ventricle just below the orifice of the tricuspid valve. [3] The left bundle branch is located in the deeper tissues. If catheter-induced complete atrioventricular block occurred during right ventricular catheterization in a patient with pre-existent LBBB, it would be much more likely that the complete atrioventricular block

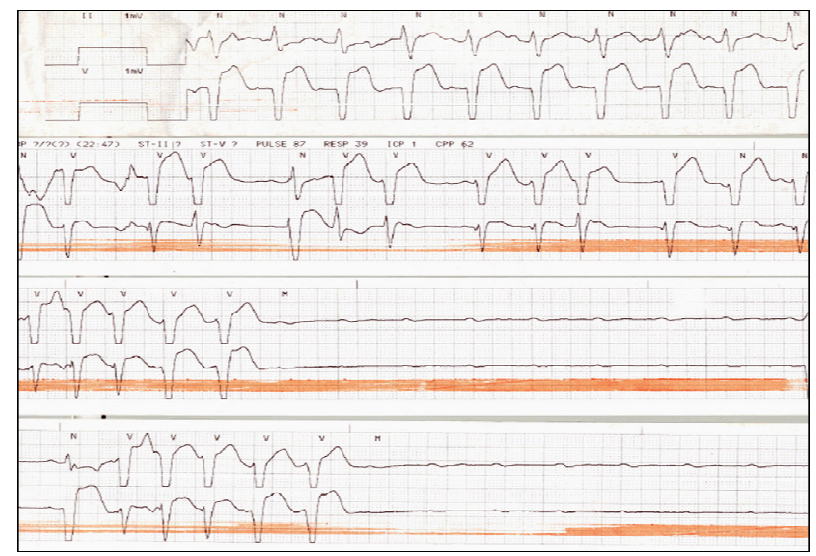

Figure 1: Electrocardiogram Strip showing the sinus rhythm progressing in to complete heart block

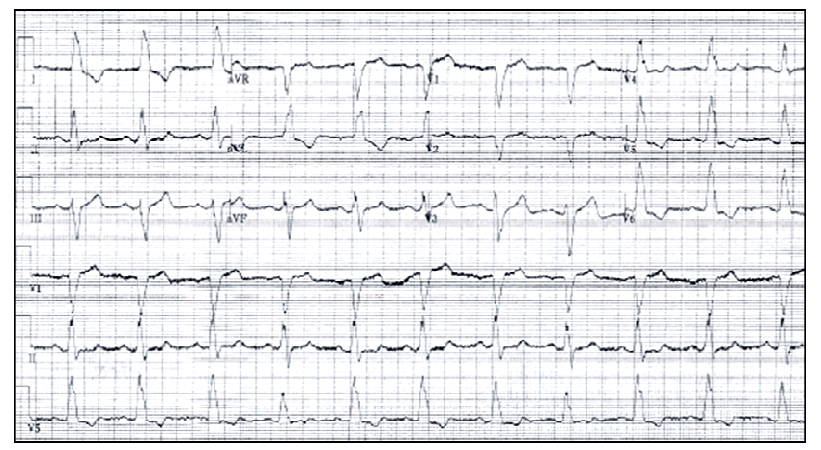

Figure 2: 12 lead Electrocardiogram showing Left Bundle Branch Block (LBBB). QRS >120 msec, broad slurred monomorphic $\mathrm{R}$ in $\mathrm{V}_{4}, \mathrm{~V}_{5}$ and $\mathrm{V} 6$ and absence of $\mathrm{Q}$ waves in I, V5 and V6

was due to bilateral bundle branch block resulting from impingement of the catheter upon the right bundle branch than from direct impingement of the catheter upon the atrioventricular node or bundle of His. [4] Transient RBBB in a patient with normal baseline ECG may remain unrecognized. [1] RBBB is usually transient (with a mean duration of less than 24 hours) and requires no intervention. [5] RBBB in a patient with pre-existing LBBB may result in lifethreatening complete heart block. These patients usually need temporary pacing during this transient block.

The functions of a guidewire during internal jugular or subclavian vein central venous catheter placement are to preserve venous access once established, direct the catheter into the superior vena cava, and prevent the catheter tip from perforating the vascular or cardiac walls. For these purposes, the length of wire advanced into the central vasculature must be enough to extend $2-3 \mathrm{~cm}$ beyond the final position of the 
Familiarize with the commonly available central line kits for the catheter and guidewire lengths and markings

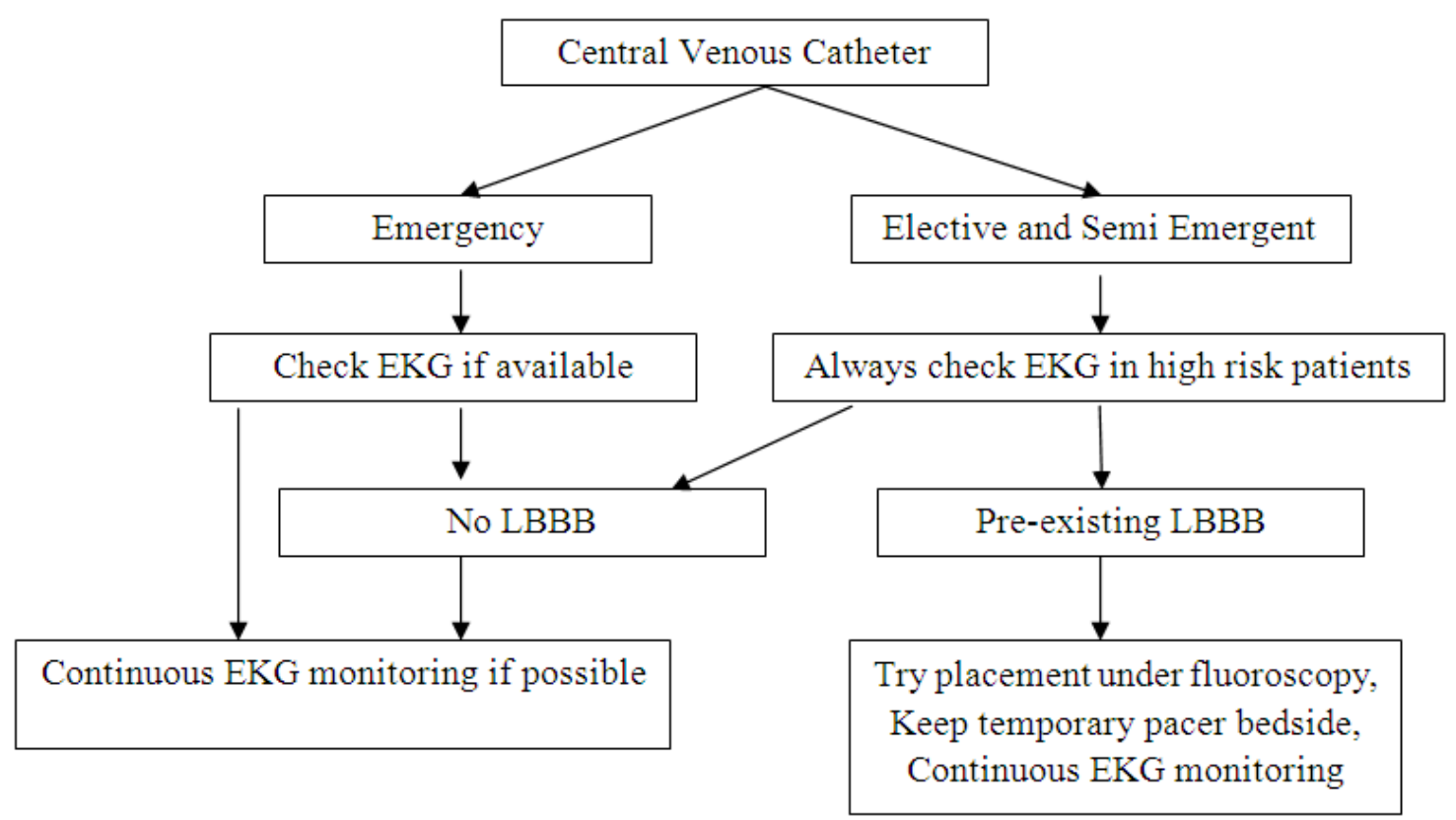

Table 1: Algorithm for upper central venous catheter placement preparedness guidelines to prevent complete heart block.

catheter tip. [6] The most difficult aspect of central venous catheter placement, and that most closely associated with procedural complications, is the establishment of initial venous access. Maintaining access, once achieved, is therefore a fundamental concern of the operating physician, and it is this concern that frequently leads to the introduction of excessive lengths of guidewire. The length of guidewires to introduce varies independently from catheter/introducer lengths. [7] The unusual complications associated with the introduction of excess guidewire into the patient during catheter placement, include wire coiling in the heart, injury to the endocardium, valve leaflets, or chordate tendineae. $[6,8]$ Guidewire complications during central venous catheter placement can be avoided if the operating physician introduces only the amount of wire necessary for safety. Studies done looking for the ideal length of the guidewire showed that the mean distance of the different access site to the junction of superior vena cava and the right atrium, where the catheter tip should ideally be placed is $18 \mathrm{~cm}$, with shortest being right internal jugular vein $(16 \mathrm{~cm})$ and longest being left subclavian vein $(21 \mathrm{~cm})$. [7] Different formulae based on patient height and insertion site can be derived to predict optimum central venous catheter insertion length. [9]

As shown in Table 1, we would like clinicians to check the EKG whenever possible before attempting different available kits we advice clinicians to familiarize with the details of catheter and guidewire lengths/markings of the available kit at their institution. Try to avoid pushing guidewire in the chambers of the heart and marking pens can be used to mark the guide wire to achieve this goal.

\section{CONCLUSION}

The case which we have provided emphasizes the possibility of complete heart block in patients with preexisting LBBB. Through our algorithm we wanted clinicians to be aware and be prepared for such an event.

$* * * * * * * *$

\section{Author Contributions}

Sachin Kumar Amruthlal Jain - Substantial contributions to conception and design, acquisition of data, drafting the article, revising it critically for important intellectual content and final approval of the version to be published

Gokulakkrishna Subhas - Substantial contributions to conception and design, acquisition of data, drafting the 
article, revising it critically for important intellectual content and final approval of the version to be published

Saba Darda - Substantial contributions to conception and design, acquisition of data, drafting the article, revising it critically for important intellectual content and final approval of the version to be published

Shukri David - Substantial contributions to conception and design, acquisition of data, drafting the article, revising it critically for important intellectual content and final approval of the version to be published

\section{Guarantor}

The corresponding author is the guarantor of submission.

\section{Conflict of Interest}

Authors declare no conflict of interest.

\section{Copyright}

(C) Sachin Kumar Amruthlal Jain et. al. 2011; This article is distributed under the terms of Creative Commons attribution 3.0 License which permits unrestricted use, distribution and reproduction in any means provided the original authors and original publisher are properly credited. (Please see www.ijcasereportsandimages.com /copyrightpolicy.php for more information.)

\section{REFERENCES}

1. Unnikrishnan D, Idris N, Varshneya N. Complete heart block during central venous catheter placement in a patient with pre-existing left bundle branch block. Br J Anaesth 2003;91(5):747-749.

2. Sprung CL, Elser B, Schein RM, Marcial EH, Schrager BR. Risk of right bundle-branch block and complete heart block during pulmonary artery catheterization. Crit Care Med 1989;17(1):1-3.

3. Matsumoto CG, Drew BJ, Ide B. Why should nurses closely monitor the ECG during insertion or exchange of a central venous catheter? Prog Cardiovasc Nurs 2000;15(1):29, 31.

4. Stein PD, Mahur VS, Herman MV, Levine HD. Complete heart block induced during cardiac catheterization of patients with pre-existent bundlebranch block. The hazard of bilateral bundle-branch block. Circulation 1966;34(5):783-791.

5. Eissa NT, Kvetan V. Guide wire as a cause of complete heart block in patients with preexisting left bundle branch block. Anesthesiology 1990;73(4):772-774.

6. Rufener JB, Andrews RT, Pfister ME, et al. An evaluation of commonly employed central venous catheter kits and their potential risk for complications of excess guidewire introduction. J Clin Anesth 2003;15(4):250-256.

7. Andrews RT, Bova DA, Venbrux AC. How much guidewire is too much? Direct measurement of the distance from subclavian and internal jugular vein access sites to the superior vena cava-atrial junction during central venous catheter placement. Crit Care Med 2000;28(1):138-142.

8. Stuart RK, Shikora SA, Akerman P, et al. Incidence of arrhythmia with central venous catheter insertion and exchange. JPEN J Parenter Enteral Nutr 1990;14(2):152-155.

9. Czepizak CA, O'Callaghan JM, Venus B. Evaluation of formulas for optimal positioning of central venous catheters. Chest 1995;107(6):1662-1664. 